\title{
REgULATING ARTIFICIAL INTELLIGENCE IN THE EUROPEAN UNION: EXPLORING THE ROLE OF PRIVATE INTERNATIONAL LAW*
}

\author{
Working paper $-31^{\text {st }}$ August 2021 \\ Please do not disseminate without the author's permission \\ Michiel Poesen, KU Leuven Faculty of Law, Belgium \\ michiel.poesen@,kuleuven.be
}

\section{Problem Statement}

This paper explores the role that private international law could play in regulating artificial intelligence (AI) in the European Union (EU). It will conclude that private international law has the potential of being a piece in a complex regulatory puzzle, which nonetheless has the potential of offering an effective contribution to ensuring accountable AI.

The emergence of Artificial Intelligence (AI) will test the current legal framework like other technologies - such as the internet - did in the not so distant past. One of the questions that will need to be addressed is the allocation of liability for AI-related harm. ${ }^{1}$ How will the risks that are related to AI be spread? Should the victim prove that the AI system was faulty, or should AI firms prove that they acted diligently? How can damage be proven? What type of AI-related damage should be compensated? These questions have a clear societal relevance: the risk of incurring liability stops excessive risk-taking and stimulates the efficient use of resources. Moreover, civil liability law 'can affect the rate and the direction of technological change', ${ }^{2}$ which indicates that it has 'dynamic effects on innovation incentives that go beyond their short term impact on the safety of the users and others' ${ }^{3}$

The quest for a balanced liability regime is complicated enough in and of itself. It will require policymakers to reflect thoroughly on the real-world impact of the liability norms they enact. Nevertheless, the endeavour becomes even more complicated when AI's transnational dimension

\footnotetext{
* I would like to thank the Stanford Existential Risk Initiative (SERI) for their generous support and Cullen O'Keefe for sharing his thoughts. Any mistakes or assertions are evidently my own and are subject to further revision of this working paper.

${ }^{1}$ Noting the policy relevance of civil liability: Herbert Zech, 'Liability for AI: public policy considerations' (2021) 22 ERA Forum 147-158.

2 Report on the safety and liability implications of Artificial Intelligence, the Internet of Things and robotics $\operatorname{COM}(2020) 64$ final.

3 ibid.
} 
is added to the equation. Take the following example: a corporation operates an AI system that scrutinizes the applications of employees (so-called 'CV-sorting software'). If such a system is biased towards selecting applicants based on gender or racial characteristics, the aggrieved applicants may want to start proceedings to obtain damages. Assume that the corporation that operates the AI system is incorporated in a jurisdiction that has permissive liability laws for AIrelated harm, and that - by contrast - the aggrieve applicants are domiciled in a jurisdiction that adopted strict liability norms for i.a. CV-sorting software. Which of the two legal regimes should be applied to decide on the applicants' claim against the operator? In other words, two legal regimes are in conflict, as they both have a claim on regulating the legal relationship between the applicant and the corporation.

Deciding which legal regime is applicable to judge on AI-related liability is the province of the legal rules on conflict of laws ('CoL') as it is known in the Anglo-Saxon world or private international law ('PrIL') as it is commonly called in Europe. These rules provide which law applies when a dispute is connected to two or more different jurisdictions. The policy impact of PrIL is readily apparent: by applying foreign law over domestic law (usually called 'forum law'), a state may concede the policies that are embedded in its own liability laws and apply those of a foreign state instead. The relationship between PrIL and policy is particularly acute in AI-related liability cases. States may seek to protect the dominant position of their domestic AI industry by shielding them from foreign liability standards, protect their domestic AI industry from stronger competitors entering the market from abroad by imposing liability standards that are stricter than the one in the foreign market, protect their societies from harmful effects that occur on its territory, stimulate innovation by allowing AI firms to benefit from the regime of their home state etc. ${ }^{4}$ As such, the PrIL is a regulatory device in the broad sense as defined by Nathalie Smuha: 'a means to intentionally influence and/or constrain the behaviour of actors, be it individuals, groups, or legal entities such as companies'.

This paper will argue that the PrIL has the potential to enhance the EU's efforts to regulate EU. To that aim, it will make two arguments. Section 2 below will outline the EU's current legislative agenda for AI-related liability, observe that the PrIL has received limited attention in the current legislative work concerning AI-related liability. Second, section 3 of this paper will consider the

\footnotetext{
${ }^{4}$ Ralf Michaels, 'Two Economists, Three Opinions? Economic Models for Private International Law - Cross Border Torts as Example' in Jürgen Basedow and Toshiyuki Kono (eds), An Economic Analysis of Private International Law (2006 Mohr Siebeck) 143-184. In what follows, I will refer to the pre-print version that was published here: https://scholarship.law.duke.edu/faculty scholarship/1234/.

5 Nathalie Smuha, 'From a 'race to AI' to a 'race to AI regulation': regulatory competition for artificial intelligence' (2021) 13 Law, Innovation and Technology 57.
} 
contribution the PrIL could make to regulating AI in the EU. It will suggest that EU PrIL is a cheap and effective tool for stimulating beneficial AI innovation while deterring AI firms and operators from excessive risk-taking in the short- and mid-term future.

\section{THE REgUlation OF AI THROUgh LiABILITY IN THE EU}

\subsection{AI Liability in the EU: State of Play}

The EU institutions are actively working to set the right regulatory standards for AI, both to curtail risks related to AI and to stimulate innovation. Among the efforts are instruments that set the product standards AI should meet, such as transparency, explainability, and respect for human rights. ${ }^{6}$ Another element in the EU's strategy is legislation concerning AI-related harm. Here, the EU parliament's Legal Affaire Committee adopted report 2020/2014(INL) with recommendations to the Commission 'on a civil liability regime for artificial intelligence' (hereafter called 'Parliament Recommendations'). ${ }^{7}$ The report contains a draft Regulation for AI-related liability that pursues a two-fold aim:

'[...] any future-oriented civil liability legal framework has to instil confidence in the safety, reliability and consistency of products and services, including in digital technology, in order to strike a balance between efficiently and fairly protecting potential victims of harm or damage and, at the same time, providing enough leeway to make it possible for enterprises, and particularly

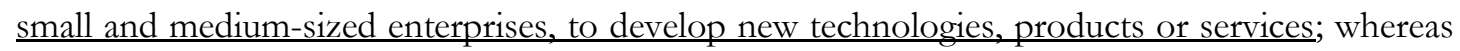
this will help build confidence and create stability for investment; whereas ultimately, the goal of any liability framework should be to provide legal certainty for all parties, whether it be the producer, the operator, the affected person or any other third party.'8

In most cases, liability requires some form of mistake or negligence on behalf of the person who allegedly is liable. ${ }^{9}$ This is where AI-related liability adds a particular flavour: AI systems operate with various degrees of autonomy. Hence, these systems are able to make autonomous decisions without human intervention. The question then is: how can a human be held accountable for the harm caused by an AI system? In others words: when can a wrong committed by AI be attributed to a human?

\footnotetext{
${ }^{6}$ See Catelijne Muller, 'The Impact of Artificial Intelligence on Human Rights,Democracy and the Rule of Law', Report Prepared in the Context of the Council of Europe's Ad Hoc Committee on AI (CAHAI) (Strasbourg: Council of Europe, 24 June 2020), < https://www.coe.int/en/web/artificial-intelligence/cahai >; Nathalie Smuha, 'From a 'Race to Ai' to a 'Race to Ai Regulation': Regulatory Competition for Artificial Intelligence' (2021) 13 Law, Innovation \& Technology.

${ }^{7}$ Report with recommendations to the Commission on a civil liability regime for artificial intelligence 2020/2014(INL), https://www.europarl.europa.eu/doceo/document/TA-9-2020-0276 EN.html.

8 ibid, recital B (emphasis added).

${ }^{9}$ Zech (n 1) 151.
} 
This a particularly tricky question to answer. In most cases, victims will lack the knowhow or means to prove that a developer or operator of an AI system committed a wrong that caused damage. ${ }^{10}$ Since establishing mistake may be so hard in many cases, the Parliament Recommendations proposed a number of liability provisions that intend to help victims establish liability. For highrisk AI systems, a vicarious liability regime is in the making. Concretely, victims who suffer damage caused by high-risk AI applications will not be required to prove fault on behalf of the applications' operator. ${ }^{11}$ For other, lower-risk AI, the Parliament Recommendations advance a fault-based liability regime. ${ }^{12}$ Even when liability is fault-based, the operator has the duty to prove that it acted with care, as opposed to the victim having to prove that the operator acted carelessly. ${ }^{13}$ The Parliament Recommendations also contain rules that take the interests of AI firms into account. Article 5 limits the amount of compensation due to victims for harm caused by high-risk AI systems. Article 8 allows the operator of an AI system to invoke force majeure to exculpate itself from harm caused by AI systems other than high-risk AI.

\subsection{Limited Attention for PrIL}

Further, the Parliament Recommendations contain a provision - Article 2(1) - that defines the Recommendations' territorial scope of applicability:

This Regulation applies on the territory of the Union where a physical or virtual activity, device or process driven by an AI-system has caused harm or damage to the life, health, physical integrity of a natural person, to the property of a natural or legal person or has caused significant immaterial harm resulting in a verifiable economic loss. ${ }^{14}$

Article 2(2) then limits party autonomy in respect of the Parliament Recommendations' regime:

Any agreement between an operator of an AI-system and a natural or legal person who suffers harm or damage because of the AI-system, which circumvents or limits the rights and obligations set out in this Regulation, concluded before or after the harm or damage occurred, shall be deemed null and void as regards the rights and obligations laid down in this Regulation. ${ }^{15}$

Two aspects of this provision are remarkable. First, Article 2(1) limits itself to a description of the Parliament Recommendations' territorial scope of applicability. It does not answer which state's law is applicable if an AI system did not cause harm or damage in the EU. In other words, Article

\footnotetext{
10 ibid 150, who raises a "knowledge problem".

${ }_{11}$ Art 4 Parliament Recommendations.

12 Art 8 Parliament Recommendations.

13 Art 8(2) Parliament Recommendations.

${ }_{14}$ Art 2(1) Parliament Recommendations.

15 Art 2(2) Parliament Recommendations.
} 
2(1) contains a so-called unilateral conflict rule, as opposed to a multilateral rule that provides which law is applicable to an abstractly defined category of disputes. ${ }^{16}$ Second, Article 2(1) defines the Parliament Recommendations' territorial scope of applicability strictly in terms of the place where the damage occurred (the so-called locus damni or place-of-injury approach). Below, I will outline why these choices deserve further consideration.

The unilateral conflict rule of Article 2(1) clearly signals the territorial ambit of the Parliament Resolution. However, its drawback is that it foregoes the opportunity to engage with the following question: which law should be applied to AI-related liability claims? For cases that are not captured by the unilateral conflict rule of Article 2(1), the Parliament resolution simply defers to the already existing PrIL framework on general liability, which is contained in the Rome II Regulation 'on the law applicable to non-contractual obligations'. ${ }^{17}$ As a matter of general principle, the Rome II Regulation subjects non-contractual claims to the law of the place where the damage occurs. ${ }^{18}$ It does so because it 'strikes a fair balance between the interests of the person claimed to be liable and the person sustaining the damage. ${ }^{19}$ However, the Regulation also enumerates a number of special conflict rules that modify or deviate from the basis rule for e.g. environmental torts, product liability, intellectual property, and unfair competition. Each of these rules is driven by openly policyoriented considerations, such as ensuring a high level of environmental protection or consumer protection. ${ }^{20}$ Unfortunately, the Parliament Recommendation did not consider whether it would be desirable to insert a special multilateral conflict rule in the Rome II Regulation for AI-related claims.

Further, the choice made in Article 2(1) of the Parliament Recommendations to apply the Recommendation's regime to AI-related harm that materialised in the EU requires closer scrutiny on two levels: policy impact and practicality. As to the rule's policy impact, the place-of-injury rule is said to allocate legislative jurisdiction to the state that has the "regulatory advantage": since the harmful consequences of a tort materialise on said state's territory, it has a strong interest in

\footnotetext{
16 William Dodge, 'Extraterritoriality and Conflict-of-Laws Theory: An Argument for Judicial Unilaterlism' (1998) 39 HarvIntlLJ 101, 107.

${ }^{17}$ Regulation (EC) No 864/2007 of the European Parliament and of the Council of 11 July 2007 on the law applicable to non-contractual obligations (Rome II) [2007] OJ L199/40, hereafter "Rome II".

18 Art 4(1) Rome II.

19 Recital 16 Rome II.

${ }^{20}$ See Horatia Muir Watt, 'The Role of the Conflict of Laws in European Private Law' in Christian Twigg-Flesner (ed), European Union Private Law (2010 Cambridge University Press) 50.

Taking stock of the policy-orientedness of contemporary EU PrIL: Marc-Philippe Weller and Alix Schulz, 'Political Private International Law: How European are Overriding Mandatory Provisions and Public Policy Exceptions?' in Jan von Hein, Eva-Maria Kieninger, Giesela Rühl (eds), How European is European Private International Law (2020 Intersentia) 285-304.
} 
regulating the activity that generated the harm. ${ }^{21}$ It is evident that the place-of-injury rule burdens those whose behaviour may incur liability. As an action's harmful effects may materialise virtually anywhere, or its effects may at least be outside of the scope of influence of economic actors, the applicable law may not always be foreseeable. ${ }^{22}$ Thus, the place-of-injury rule is paired with relatively high costs: an economic actor, such as an AI producer or an operator of an AI system, who wishes to avoid liability, has to speculate in which jurisdictions her activities may cause damage. Moreover, the final phrase of Article 2(1) of the Parliament Recommendations lacks precision. It provides that the draft framework applies when AI 'caused significant immaterial harm resulting in a verifiable economic loss' in the EU. This wording seems difficult to operate in practice, as it does not detail when immaterial harm that caused verifiable economic loss in the EU is 'significant' enough to trigger the draft regime's applicability.

The interim conclusion therefore is that the Parliament Recommendations has not seized the opportunity to open the debate about the role of EU PrIL in regulating AI.

\section{Unearthing the Regulatory Potential of PrIL}

What, then, could be EU PrIL's contribution to regulating AI in the EU? Below I will argue that the PrIL can help realise the EU's goal of finding a balance 'between efficiently and fairly protecting potential victims of harm or damage and, at the same time, providing enough leeway to make it possible for enterprises [...] to develop new technologies, products or services.' In this section, I will claim that EU PrIL offers a limited but cheap and effective tool to facilitate AI innovation while maintaining a decent level of accountability of AI firms on the short to mid term. First, I will outline the rules that are contained in contemporary EU PrIL. These rules offer templates for a PrIL rule that balances the need to foster innovation as well as ensure accountability, which could be used as a source of inspiration for a bespoke AI-related PrIL rule (section 3.1.). Second, I will argue that in particular article 8 of the Rome II Regulation - which allows victims of environmental torts to choose the applicable law to a certain extent - might offer an appropriate foundation for an AI-specific PrIL rule (section 3.2.).

\subsection{The Options: Contemporary EU PrIL as a Source of Inspiration}

Drafting the EU regime for AI-related civil liability offers a unique occasion to reflect about an AIspecific multilateral conflict rule. Below, I will consider a few options, drawing inspiration from the relatively diverse array of existing multilateral conflict rules in contemporary EU PrIL. Then I

\footnotetext{
${ }^{21}$ Michaels (n 4).

22 ibid 15.
} 
will propose to draw inspiration from Article 5 of the Rome II Regulation, as this provision deploys a technique that allows striking a balance between protection and innovation. In a final step, I will highlight that excepting the application of foreign law to AI-related liability claims can be a productive tool for AI governance.

The first option is to adopt the place-of-injury rule, which was touched upon in the preceding section already. As observed above, the place-of-injury rule allows the law of the place where the consequences of a harmful act are felt to regulate the remedy. In essence, the assumption here is that the place of injury has a regulatory interest in deciding whether and how a tort should be remedied. By contrast, the place-of-injury rule would impose high costs on AI firms, as they are not always able to foresee where an AI system might cause harm.

According to the second option, the law of the place of conduct (the so-called lex loci delicti commissi) might be applied. For AI-related liability claims, the place of conduct may be the place where an AI-system was developed or operated. This place-of-conduct rule is favoured by those who assume that the conflict of laws should ensure foreseeability. ${ }^{23}$ Under this rule, AI developers and operators will be able easily to predict the law that applies to their liability abroad. In essence, they carry their home law along with them, even when their activities have harmful consequences outside of their home jurisdiction. The place-of-conduct rule also bears on market competition. If economic actors can enter a market while remaining subject to the more lenient liability rules of their home state, they have a competitive advantage over domestic economic actors of the target market. ${ }^{24}$ Of course, civil liability is just one of the legal factors that informs an economic actor's decision to relocate its operations to jurisdiction that has weak liability standards, alongside i.a. fiscal law, government incentives, the available corporate forms, bankruptcy law, labour law etc. ${ }^{25}$

The third option can be called the "choice principle". It mixes the place-of-injury rule and placeof-conduct rule by allowing the claimant to choose which of these two laws to rely on. Article 8 of the Rome II Regulation gives such a choice to victims of environmental torts. This provision is inspired by the right to environmental protection, 'which provides that there should be a high level of protection based on the precautionary principle and the principle that preventive action should be taken, the principle of priority for corrective action at source and the principle that the polluter pays'. Said right 'fully justifies the use of the principle of discriminating in favour of the person sustaining the damage'. ${ }^{26}$

\footnotetext{
23 Supra (n 22).

${ }^{24}$ Michaels (n 21) 20.

${ }^{25}$ See Smuha (n 5) 5-6.

${ }^{26}$ Recital 25 Rome II.
} 
The fourth and final option holds the middle between the place-of-injury rule and the place-ofconduct rule: the "market-targeting rule". This approach currently applies to product liability claims in the EU pursuant to Article 5 of the Rome II Regulation. According to this rule, a person who sustained damage can rely on the law of the country where she is domiciled, provided that the tortfeasor directed its activities towards the victim's market. Failing this, the law of the place of acquisition of the product will apply, insofar as the injurer directed its activities towards the market of the place of acquisition. Failing this, the law of the place of damage applies, again provided that the product was marketed in that country. This cascaded rule is built on the assumption that consumers usually will be affected by a harmful product in the country of their residence. It adds an important safeguard for the injurer compared to a pure place-of-injury approach. Indeed, the law of the domicile of the defendant who is claimed to be liable applies if she 'could not reasonably foresee the marketing of the product, or a product of the same type' in one of the aforementioned locations. A mix of underlying considerations informed this complex cascade rule:

The conflict-of-law rule in matters of product liability should meet the objectives of fairly spreading the risks inherent in a modern high-technology society, protecting consumers' health, stimulating innovation, securing undistorted competition and facilitating trade. Creation of a cascade system of connecting factors, together with a foreseeability clause, is a balanced solution in regard to these objectives. The first element to be taken into account is the law of the country in which the person sustaining the damage had his or her habitual residence when the damage occurred, if the product was marketed in that country. The other elements of the cascade are triggered if the product was not marketed in that country, without prejudice [...] to the possibility of a manifestly closer connection to another country.

\subsection{Reflections About a Choice-of-Law Rule for AI}

It is difficult to make a firm normative claim about which of the aforementioned PrIL rules is the best for AI-related liability claims. To guide my thought process, I will draw inspiration from the insights of "effective altruism" (EA). EA is a practical commitment to "using evidence and reason to figure out how to benefit others as much a possible, and taking action on that basis." ${ }^{27}$ Benefiting others is usually understood in a welfarist way, which means that actions and policies should be aimed at increasing human welfare. ${ }^{28}$ In this respect, there is a broad consensus within the EA community that the development of $\mathrm{AI}$ is one of the most pressing topics: AI holds a promise to create wealth and welfare the likes of which are unknown to humanity, but also entails severe risks

\footnotetext{
${ }^{27}$ William MacAskill, 'The Definition of Effective Altruism' in Hilary Greaves and Theron Pummer (eds), Effective Altruism: Philosophical Issues (2019 Oxford University Press) 13.

28 ibid 21.
} 
for human safety, social stability and even human existence itself. Applied to AI systems, EA foregrounds the importance of managing these AI-related risks as well as fostering the potential AI has to improve human lives. ${ }^{29}$

With this commitment in mind, it transpires that the "choice principle" of Article 8 of the Rome II Regulation could provide a fruitful basis for an AI-specific PrIL rule. I shall attempt to make my point by replying to the main critique on the "choice principle": by favouring the victim, it overregulates transnational activity, which in turn may petrify innovation through $\mathrm{AI}$ in the EU. ${ }^{30}$ However, I will argue that whether AI will be applied to the benefit of welfare in EU Member States will largely depend on others factors, such as the size of the potential market, product standard regulations, the presence of trade barriers, the availability of a sufficiently trained workforce, or the granting of tax benefits. ${ }^{31}$ If these factors sufficiently incentivise actors to operate or market AI systems in the EU, then a generous choice-of-law rule such as the "choice principle" may, everything considered, not impede innovative AI systems from reaching the EU market. Further support for this hypothesis can be found in the so-called "Brussels effect", which is a theory that was first articulated by Anu Bradford. ${ }^{32}$ The "Brussels effect" refers to the idea that EU regulation manages to spread throughout the world (particularly where actors cannot easily isolate their economic activities geographically), since the benefits for non-EU firms that are related to entering the EU market outweigh the costs of having to comply with EU regulation that is more stringent than that of their home jurisdiction. ${ }^{33}$ It is advanced that AI firms may have an overwhelming interest in operating their AI systems in the EU, which may outweigh the cost of complying with at least two liability regimes under the "choice principle". If this is correct, then EU PrIL has the potential to ensure a high level of accountability for AI-related harm, while not preventing AI from bringing about an increase in human welfare.

If it is true that the "choice principle" is but one factor in the regulation of AI that will not necessarily prevent AI firms and operators from entering the EU market, then the principle might bring an added benefit. It has the potential to create a "venue for contestation", a term that was coined by Robert Wai in $2008 .{ }^{34}$ Contestation refers to "[seeking] retribution and compensation, [making] arguments, to [publicizing] bad conduct, and generally to [contesting] behavior of private

\footnotetext{
29 Robert Wiblin, 'Positively shaping the development of artificial intelligence' (March 2017, 8000 Hours) https://80000hours.org/problem-profiles/positively-shaping-artificial-intelligence/

30 See Roxana Banu, 'Conflicting Justice in Conflict-of-laws' (2020) 62 Vanderbilt Journal of Transnational Law 461, 522.

${ }^{31}$ See Smuha (n 5) 14, noting that '... the costs of moving AI resources from one jurisdiction to another (be it AI talent, capital or infrastructure) are unlikely to be negligible.'

32 Anu Bradford, The Brussels Effect (2020 Oxford University Press).

33 ibid 25-26.

${ }^{34}$ Robert Wai, 'The Interlegality of Transnational Private Law' (2008) 71 Law and Contemporary Problems 107.
} 
actors, such as multinational corporations that engage in cross-border conduct." ${ }^{35}$ Wai raised that "[this] kind of contestation is needed to address governance gaps opened up in the international order where many problems are globalized but political and legal forms remain primarily situated in the nation-state, where national governments tend to be parochial in their regulatory focus, and where international institutions, such as the World Trade Organization, are only weakly empowered to address the full range of cross-border problems that arise in a global society." 36 The idea of "contestation" seems particularly astute in the context of regulating AI systems. Since a global uniform legal framework for AI is far away, ${ }^{37}$ national and regional legal frameworks will emerge alongside each other. ${ }^{38}$ It is more than likely that these frameworks will take various approaches, e.g. as to the question of the allocation of liability and the calculation of damages. ${ }^{39}$ In such a context, victims or civil society may take up an important role in contesting the harmful effects that are generated by operators of AI systems. The EU can offer such actors a useful venue for contestation by allowing them to rely on two civil liability regimes under the choice principle. Citizens and social interest groups then benefit from a high level of protection, which they can use to raise awareness of existential dangers and risks related to AI systems. Admittedly, this is a decentralised form of AI governance at best, and one that grapples with the traditionally nonpolitical nature of PrIL in Europe. ${ }^{40}$ Yet previous experiences have shown that transnational litigation in civil courts bears the promise of being a highly effective means for raising public awareness and bringing relevant information in the open. ${ }^{41}$ The potential of EU PrIL to play the same role in AI governance should at least be contemplated.

\section{CONCLUSION}

AI will require institutions to rethink and probably reshuffle their legal framework. One aspect of the law that will require rethinking is civil liability, since AI raises particular issues concerning the allocation of risk. At the EU level, such a new liability for AI-related harm is slowly emerging. While a large part of the attention has gone to the principle on which liability should be based, the

\footnotetext{
35 ibid 117.

36 ibid 117-118.

${ }^{37}$ Despite efforts at e.g. UNESCO, whose Ad Hoc Expert Group (AHEC) raises the objective of ' ... harmonizing AIrelated legal norms across the globe...', see its 'First draft of the Recommendation on the Ethics of Artificial Intelligence' (SHS/BIO/AHEG-AI/2020/4 REV.2, https://unesdoc.unesco.org/ark:/48223/pf0000373434).

38 Pekka Ala-Pietilä and Nathalie Smuha, 'A Framework for Global Cooperation on Artificial Intelligence and its Governance' in Bertrand Braunschweig and Malik Ghallab (eds), Reflections of AI for Humanity (2021 Springer) 26-27 (preprint available at https://papers.ssrn.com/sol3/papers.cfm?abstract $\mathrm{id}=3696519$ ).

39 As noted by Bookman, 'decisional disharmony' can be expected: Pamela Bookman, 'The Unsung Virtues of Global Forum Shopping’ (2016) 92 NotreDameLRev 579, 601.

${ }^{40}$ See Jacco Bomhoff and Anne Meuwese, ‘The Meta-regulation of Transnational Private Regulation' (2011) 38 Journal of Law and Society 138, 154-155.

${ }^{41}$ Wai (n 34) 118.
} 
question as to the applicability of the regime in cross-border has received comparatively little consideration. This paper interrogated whether EU private international law - i.e. the field that governs the applicability of private law in transnational cases - could contribute to AI governance in the EU. Two take-aways result from this enquiry. First, current legislative work in the EU on AI-related liability has paid little attention to the role of private international law. It only entertained the territorial scope of applicability of a potential novel legislative instrument (under the guise of a unilateral conflict-of-laws rule), without interrogating whether and when foreign law could apply to AI-related liability cases. The second take-away is that EU private international law bears the potential of supporting the EU's efforts to regulate AI. By adopting a choice-of-law rule that subject operators or developers of AI systems to more than one liability regimes, the EU could create a so-called "venue for contestation" that allows citizens and interest groups to address the negative externalities of AI without compromising beneficial AI innovation. 